\title{
Autologous bone marrow stem cell transplantation for the treatment of postoperative hand infection with a skin defect in diabetes mellitus: A case report
}

\author{
YIHONG LIU $^{1,2}$, YUCHEN LIU ${ }^{2}$, PUJIE WANG ${ }^{2}$, HAOMING TIAN $^{1}$, JIANZHONG AI $^{3}$, \\ YANGBO LIU ${ }^{2}$, YI ZHOU ${ }^{2}$, ZHONGWEN LIU ${ }^{2}$, WENJUN GUO ${ }^{2}$ and SHENKE YANG ${ }^{2}$ \\ ${ }^{1}$ Department of Endocrinology and Metabolism, West China Hospital, \\ West China Medical School, Sichuan University, Chengdu, Sichuan 610041; \\ ${ }^{2}$ Diabetic Centre of Control and Prevention, The People's Liberation Army 520 Hospital, Mianyang, \\ Sichuan $621000 ;{ }^{3}$ Core Facility of Genetically Engineered Mice, State Key Laboratory of Biotherapy and Cancer Center, \\ West China Hospital, West China Medical School, Sichuan University, Chengdu, Sichuan 610041, P.R. China
}

Received August 28, 2013; Accepted February 7, 2014

DOI: $10.3892 / 01.2014 .1998$

\begin{abstract}
Among stem cells, autologous mesenchymal stem cells (MSCs) are ideal for transplantation by virtue of limited rejection reactions and marked proliferative ability. This study presents a novel method by which MSCs were harvested from the bone marrow of a patient who presented with severe post-traumatic infection and a non-healing skin defect in the hand, secondary to uncontrolled diabetes mellitus (DM). An autologous MSC suspension was injected into the persistent skin defect after stabilizing the blood glucose level and appropriate infection control. During the course of a regular 18-month postoperative follow-up, the patient exhibited immediate recovery with no transplant-associated complications, as well as no evidence of tumorigenicity. Thus, transplantation of autologous MSCs may play a role in the clinical application of stem cells, particularly for treatment of skin defects following surgery in cases of DM and for those caused by various other traumas.
\end{abstract}

\section{Introduction}

There are two types of stem cell in the human bone marrow: Hematopoietic stem cells (HSCs) and mesenchymal stem cells (MSCs). HSCs primarily maintain hematopoietic functions, while MSCs have the ability to differentiate into various mesoderm- and neuroectoderm-derived cells. MSCs are

Correspondence to: Dr Haoming Tian, Department of Endocrinology and Metabolism, West China Hospital, West China Medical School, Sichuan University, 37 Guoxuaxiang, Chengdu, Sichuan 610041, P.R. China

E-mail: hmtian999@126.com

Key words: bone marrow mesenchymal stem cell, autotransplantation, diabetes mellitus, skin defect, tumorigenicity multipotent stromal cells with high proliferative ability that can differentiate into a variety of cell types, including vascular endothelial cells, islet cells and hepatocytes, under certain conditions. Autologous MSCs are considered ideal seed cells, since they can be conveniently obtained without ethical issues and are characterized by limited rejection and marked proliferative ability. With the development of cell and tissue engineering, MSCs, as cell sources in cell and gene therapy as well as tissue engineering, are a key area of study $(1,2)$. In 2002, bone marrow HSC transplantation was applied in the treatment of peripheral angiopathy for the first time $(3,4)$. It has been demonstrated in animal experiments that autologous bone marrow mononuclear cells implanted in ischemic limbs can differentiate into vascular endothelial cells to promote local angiogenesis, suggesting that stem cell transplantation can be used for the treatment of ischemic limb diseases and severe skin defects in cases of diabetes mellitus (DM) (5-7).

Skin is an important part of the body in that it maintains homeostasis and acts as a barrier to the invasion of microorganisms and harmful substances. However, various injuries, including trauma, war wounds, and burn and earthquake injuries often cause extensive skin defects, resulting in bacterial invasion and reproduction, which may also induce water and electrolyte disturbance, septic shock, multiple organ dysfunction and mortality. Currently, auto-skin grafting is the main approach to treating extensive burns or skin defects following trauma (8). However, such a method inevitably results in complications through causing trauma to the normal skin. It is therefore urgent that the methods of repairing extensive skin defects are improved.

$\mathrm{DM}$ is a chronic metabolic disorder. Difficulty in skin wound healing and skin defects are the most common chronic complications of diabetes. Diabetic foot, as a representative complication, causes disability as a result of amputation. Although numerous hypotheses have been presented, the mechanism of the development of refractory skin wounds under hyperglycemic conditions remains unclear. Oxidative stress (OS) is considered an important common mechanism (9). 
However, wound healing is a complicated process involving three stages of inflammatory reactions, cell proliferation, tissue maturity and reconstruction. In DM, nonenzymatic glycosylation accelerates, and the level of glycoxidation end-product increases at advanced stages, which interferes with endothelial cell-leukocyte interactions, inhibits the functions of monocytes/macrophages, reduces cytokine secretion capacity and prolongs the duration of infiltration of these cells in the wound. This in itself can lead to a refractory skin defect (10).

As comprehensive therapies, including conventional anti-infection therapy, wound debridement and dressing changes, and glucose-lowering therapy were ineffective for treatment of postoperative wound infection in the hand in the present report, an extended amputation, right hand amputation or local autologous skin transplant for the skin defect was recommended. However, the patient refused these recommendations being concerned that new skin defects would arise as a result of harvesting skin grafts from healthy and intact skin. The patient chose to undergo autologous stem cell transplantation on the understanding that this option would cause minimal injury and pain. Written, informed consent was obtained from the patient prior to autologous bone marrow MSC transplantation on the skin defect of the right hand in August, 2010. The clinical efficacy and complications, including transplantation-associated rejection reactions and tumorigenicity of transplanted autologous bone marrow MSCs, were investigated for a period of 18 months. This program was approved by the Scientific and Ethics Committee of Sichuan University (Chengdu, China).

\section{Case report}

Case summary. A 64-year-old male farmer was admitted to the Department of Hand and Foot Surgery at the People's Liberation Army 520 Hospital (Mianyang, China) on July 22nd, 2010 complaining of elevated blood glucose levels for three years and right hand pain and swelling following trauma for longer than half a month. The patient was diagnosed with DM at a local hospital three years previously, but had not adhered to regular treatment due to personal financial problems. Therefore, blood glucose levels had remained largely unchecked. Notes from a previous hospital visit indicated that the random blood glucose level was $16.08 \mathrm{mmol} / \mathrm{l}$ and percentage glycosylated hemoglobin was $12.7 \%$. Approximately half a month previously, the patient had accidentally cut his right hand at work, producing a non-healing wound resulting in the back of the right hand becoming swollen and painful, together with infection, necrosis and a large defect in the skin of the root of the right forefinger. Debridement and sutures at a local hospital achieved unsatisfactory results, and the case was transferred to the People's Liberation Army 520 Hospital. On admission, a 5.0x3.0 cm-deep skin defect in the metacarpophalangeal joint of the forefinger and back of the right hand back with flavescent fishy effusions was observed. The bone was exposed and visible through the defect, the tendon was ruptured and the distal tendon was pale. Poor local blood supply was observed, and the patient was suffering from local numbness. The defect was irregular and the contusion was severely contaminated. The case was preliminarily diagnosed as wound infection following trauma, vascular, nerve and tendon injuries and complex tissue defects in the right hand, and DM and diabetic nephropathy. Following intensive insulin pump therapy, anti-infection therapy and local wound debridement and dressing changes for one week, blood glucose became well controlled (Table I) but the local wound did not improve. Therefore, amputation of the right forefinger was performed on August 7th, 2010. Following surgery, the surgical wound in the right hand developed suppuration and infection and was poorly healed, with a size of $\sim 5.0 \times 3.0 \mathrm{~cm}$. As the condition had not improved following comprehensive therapy, including anti-infection therapy, wound dressing changes and glucose-lowering therapy, the case was transferred the Diabetic Centre of Control and Prevention for further treatment. After group consultation and discussion, a choice of extended amputation, right hand amputation or local autologous skin grafting was recommended. However, as discussed previously, the patient refused these recommendations and instead opted for autologous MSC transplantation. On August 5th, 2010, patient bone marrow was harvested under local anesthesia and MSCs were separated, cultured and amplified in vitro for 14 days. The third generation of MSCs was prepared as a stem cell suspension with a concentration of $6 \times 10^{6}$ cells $/ \mathrm{ml}$. On August 19th, 2010, autologous bone marrow MSC transplantation was performed after the patient provided written, informed consent. No common complications or adverse reactions associated with transplantation were observed. On day 10 after surgery, the patient was completely healed and was discharged from hospital. Before and after autologous stem cell transplantation, blood glucose levels had almost reached the standard range (Table I).

Reagents. Lymphocyte separation medium was purchased from Shanghai Qcbio Science \& Technologies Co., Ltd. (Shanghai, China). Xylene and hematoxylin and eosin (H\&E) stain were purchased from Shanghai Source Leaf Biological Technology Co., Ltd. (Shanghai, China). Complete Dulbecco's modified Eagle's medium and fetal bovine serum were purchased from Invitrogen Life Technologies (Carlsbad, CA, USA). Penicillin and streptomycin were purchased from Nanjing KeyGEN Biotech Co., Ltd. (Nanjing, China).

Collection of autologous bone marrow. Following completion of pre-operative examinations, the patient fasted on the morning of the surgery. The patient was placed in a prone position and conventional disinfection and sterilization procedures were followed. Blood bags and storage solution were prepared. Bone marrow was collected from the bilateral posterior superior iliac spine under local anesthesia. Approximately $10 \mathrm{ml}$ bone marrow was collected from each of three sites at $1-\mathrm{cm}$ intervals along the lateral superior edge of the ilium (a total of $30 \mathrm{ml}$ bone marrow).

Separation of bone marrow MSCs. The collected bone marrow samples were diluted with twice the volume of physiological saline on a laminar flow cabinet, and the resulting suspension was transferred to a lymphocyte separation medium (at a ratio of $2: 1$ ). The obtained solution was centrifuged at $640-800 \mathrm{x} \mathrm{g}$ for $20 \mathrm{~min}$ at $20^{\circ} \mathrm{C}$. The white membrane layer in the $15 \mathrm{ml}$ centrifuge tube was gently transferred to a clean Eppendorf tube, washed twice with double the volume of 
Table I. Blood glucose levels during two hospital admissions.

\begin{tabular}{|c|c|c|c|c|c|c|}
\hline \multirow[b]{2}{*}{ Date } & \multirow[b]{2}{*}{$\begin{array}{l}\text { Diabetes mellitus } \\
\text { treatment protocol }\end{array}$} & \multicolumn{5}{|c|}{ Blood glucose level, mmol/l } \\
\hline & & $\begin{array}{l}\text { Prior to } \\
\text { breakfast }\end{array}$ & $\begin{array}{l}2 \mathrm{~h} \text { after } \\
\text { breakfast }\end{array}$ & $\begin{array}{l}2 \mathrm{~h} \text { after } \\
\text { lunch }\end{array}$ & $\begin{array}{l}2 \mathrm{~h} \text { after } \\
\text { supper }\end{array}$ & 2:00 AM \\
\hline $2010-07-29^{a}$ & $\begin{array}{l}\text { Intensive insulin pump therapy } \\
\text { (Humalog at } 63 \mathrm{U} / \text { day) }\end{array}$ & 5.2 & 8.5 & 8.7 & 7.1 & 5.2 \\
\hline $2010-08-12^{\mathrm{a}}$ & $\begin{array}{l}\text { Humalog Mix } 50 \\
(16,12 \text { and } 14 \text { units })\end{array}$ & 6.1 & 5.2 & 10.5 & 7.8 & 8.8 \\
\hline $2010-08-19^{b}$ & $\begin{array}{l}\text { Humalog Mix } 50 \\
(16,13 \text { and } 14 \text { units })\end{array}$ & 4.8 & 10.4 & 8.8 & 8.7 & 8.8 \\
\hline $2010-08-20^{c}$ & $\begin{array}{l}\text { Humalog Mix } 50 \\
(16,12 \text { and } 14 \text { units })\end{array}$ & 5.7 & 6.7 & 8.1 & 9.3 & 5.5 \\
\hline $2010-09-02^{\mathrm{d}}$ & $\begin{array}{l}\text { Humalog Mix } 50 \\
\text { (16,14 and } 14 \text { units) }\end{array}$ & 5.7 & 8.1 & 7.9 & 7.9 & 7.1 \\
\hline $2012-02-29^{\mathrm{e}}$ & $\begin{array}{l}\text { Metformin } \\
\text { (500 mg, } 3 \text { times/day) }\end{array}$ & 7.0 & 16.4 & 12.7 & 11.8 & Unmeasured \\
\hline $2012-03-05^{\mathrm{e}}$ & $\begin{array}{l}\text { Metformin } \\
(850 \mathrm{mg}, 3 \text { times/day) }\end{array}$ & 6.1 & 10.0 & 8.1 & 9.1 & 8.9 \\
\hline
\end{tabular}

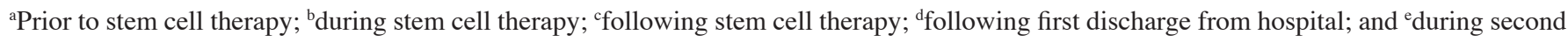
hospital admission.

phosphate buffer solution ( $\mathrm{pH} 7.2-7.4$ ), and centrifuged at $450 \mathrm{x}$ g for $10 \mathrm{~min}$. Mononuclear cells were separated, amplified in vitro for 14 days and passaged to the third generation. The precipitate was diluted with $30 \mathrm{ml}$ physiological saline to produce a stem cell suspension containing $6 \times 10^{6}$ cells $/ \mathrm{ml}$. Of this suspension, $1 \mu \mathrm{l}$ was used to count cells and observe the cell morphology under a microscope.

Autologous bone marrow MSC transplantation. Autologous bone marrow MSC transplantation was performed under strictly aseptic conditions in the operating room. The infection site on the right hand was routinely debrided and the MSC suspension was transplanted into the wound by injection of $0.3-0.5 \mathrm{ml}$ in each site at $1.0-\mathrm{cm}$ intervals. The injection depth was $0.5-1.0 \mathrm{~cm}$. Following injection, the wound was protected with sterile gauzes and bandages.

Observation of wound healing. The wound surface of the skin defect prior to surgery and during recovery was recorded using a digital camera, and any presence of rejection reactions, hand inflammation and swelling was recorded.

$H \& E$ staining. Skin tissues were surgically collected, fixed in $4 \%$ paraformaldehyde overnight, dehydrated with a series of ethanol solutions, embedded in paraffin and cut into sections. The sections were deparaffinized with xylene, rehydrated, stained with H\&E stain and enveloped. The pathological changes of the skin were observed using the Olympus BX41 microscope (Olympus Corporation, Tokyo, Japan).

Observations following transplantation. The pain, coldness and numbness in the right hand improved $24 \mathrm{~h}$ after transplantation. After $48 \mathrm{~h}$, the purulent secretions from the wound had clearly decreased, local swelling alleviated, local ischemia gradually improved and the wound shrank from $5.0 \times 3.0 \mathrm{~cm}$ to $4.0 \times 1.0 \mathrm{~cm}$ (Fig. 1A and B). After $96 \mathrm{~h}$, the wound was $4.0 \times 0.5 \mathrm{~cm}$ in size (Fig. 1C) and local ischemia gradually improved. After $192 \mathrm{~h}$, the wound had completely healed (Fig. 1D). Therefore, following autologous bone marrow MSC transplantation, the injection puncture wounds healed rapidly. No local abnormal symptoms or signs were observed, and blood, urine and stool tests, and biochemical examinations (including liver and renal function tests) revealed no systemic abnormalities.

The patient was readmitted to the People's Liberation Army 520 Hospital for examination 18 months after surgery. The local condition of the hand that underwent autologous bone marrow MSC transplantation was stable and no transplantation-associated rejection reactions had occurred. A sample of local full-thickness skin tissue, at a size of $0.7 \times 0.3 \times 0.2 \mathrm{~cm}$, was cut from the healed wound (Fig. 2) for pathological examination. H\&E staining revealed mild epidermal hyperplasia with hyperkeratosis, increased pigment in local basal cells, hyperplasia and degeneration of collagen fibers, and minor infiltration of lymphocytes in the small perivascular regions of the superficial dermis. These observations are not significantly different from the pathology of normal skin tissues. In addition, there was no evidence of tumor formation (Fig. 3).

\section{Discussion}

It has been demonstrated that skin constructed by MSCs used as seed cells can significantly promote healing of skin defects. Such wounds possess full-thickness skin structures following repair (11-13). During the process of wound healing, MSCs are closely involved in the formation of small blood vessels in the granulation tissue (14). MSCs can differentiate into vascular 

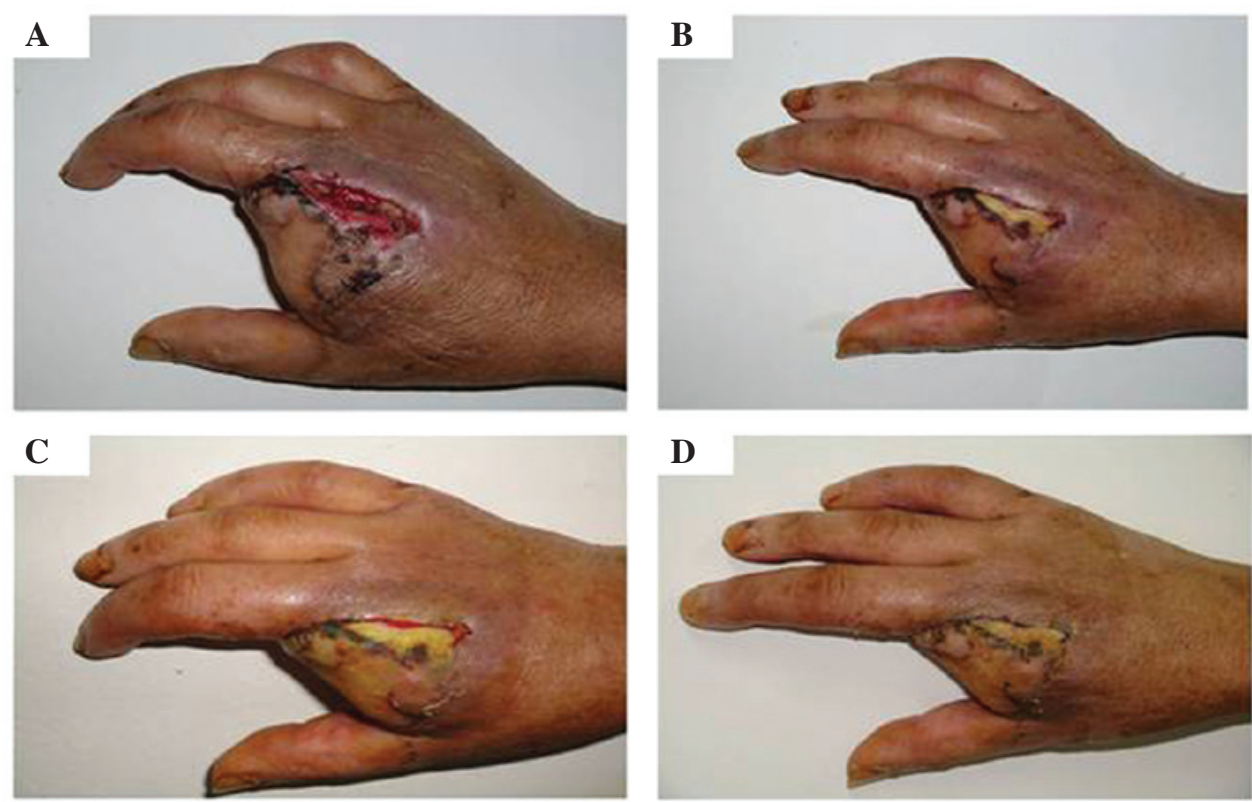

Figure 1. Transplantation sites before and after surgery showing significant improvement in swelling and inflammation. (A) Prior to surgery, the wound was $5.0 \times 3.0 \mathrm{~cm}$ in size; (B) $48 \mathrm{~h}$ after surgery, the wound was $4.0 \times 1.0 \mathrm{~cm}$ in size; (C) $96 \mathrm{~h}$ after surgery, the wound was $4.0 \times 0.5 \mathrm{~cm}$ in size; and (D) $192 \mathrm{~h}$ after surgery, the wound had healed.
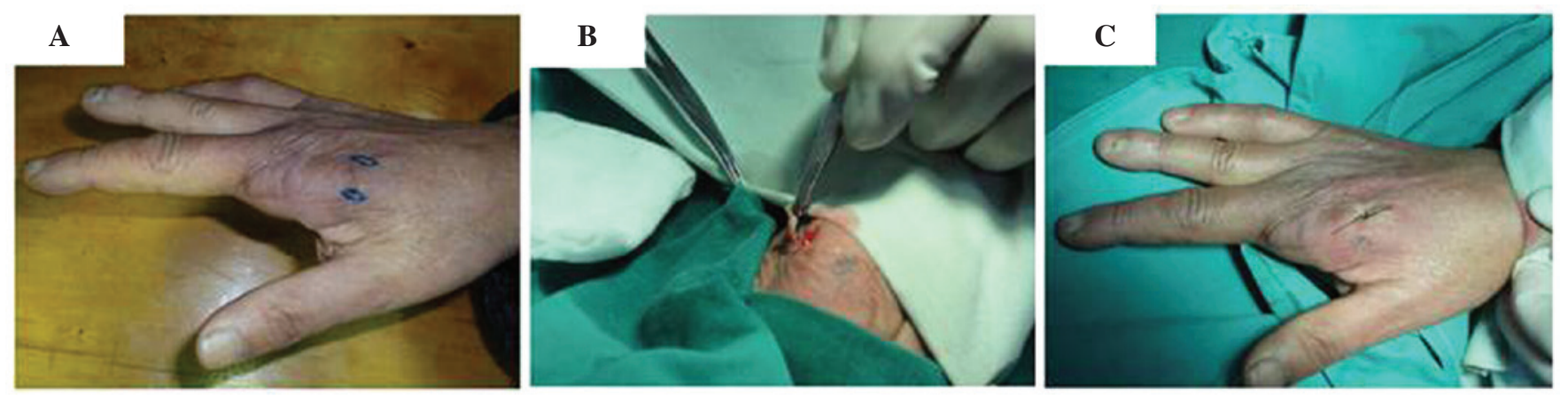

Figure 2. Histological examination of the skin (18 months post-surgery). (A) The site on local healed skin where tissues are sampled for biopsy; (B) local skin is sampled for biopsy; and (C) biopsy site sutured after tissue sampling.
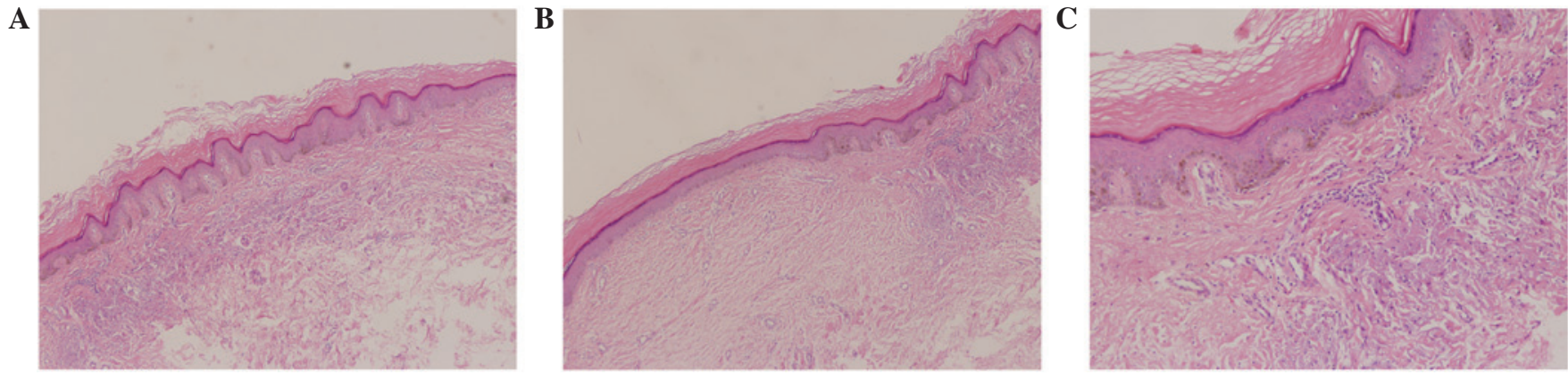

Figure 3. Histopathological examination of hematoxylin and eosin-stained skin from the healed wound. (A) Normal skin (magnification, x100); (B) mild epidermal hyperplasia with hyperkeratosis and increased pigment in local basal cells (magnification, x100); and (C) mild epidermal hyperplasia with hyperkeratosis, hyperplasia and degeneration of collagen fibers, and minor infiltration of lymphocytes in the small perivascular regions (magnification, x200).

endothelial cells and are involved in repair of the skin defect in the wound micro-environment. It has been reported that MSCs may also be used for treatment of ischemic diseases (15-18). In a study by Subrammaniyan et al (19), injection of bone marrow-derived mononuclear cells had satisfactory efficacy in the treatment of six cases of DM with critical limb ischemia and skin defects, and amputation was avoided in all patients undergoing autologous bone marrow-derived mononuclear cell injection.

However, it is debated whether MSCs transplanted into the body may induce various gene mutations resulting in 
infinite cell proliferation and growth similar to tumor cells or even induce tumorigenesis (20-22). It has been demonstrated that embryonic stem cells (ESCs) isolated from rodents and humans are very similar to embryonal carcinoma cells, and their potent tumorigenicity has the potential to lead to teratomas (23). Stem cell tumorigenicity is the key obstacle to the safe use of stem cell-based regenerative therapies. Although certain adult stem cell therapies appear to be safe, they have only a narrow range of application in human disease. Human induced pluripotent stem cells are predicted to possess tumorigenic potential equal to or greater than that of ESCs (23).

Based on the aforementioned issues surrounding stem cell tumorigenicity, further follow-up observation and clinical study were conducted for the present patient. Pathological examinations of the full-thickness skin tissues from the healed wound revealed no significant difference from the pathology of the normal skin tissue, and no tumor formation was identified (Fig. 3). Thus, we hypothesize that autologous transplantation of MSCs amplified in vitro may be a novel, simple and effective approach to the treatment of severe skin defects and infection. In addition, such therapy presents a solution to the problems of severe wound infection and poor local blood supply in DM without transplantation-associated rejection and tumor formation, thereby achieving the goals of treatment. In addition, the present study provides a novel method for the treatment of other skin defects caused by various traumas, including burns, knife wounds and earthquake injuries, using autologous MSC transplantation in clinical practice.

The identification and study of stem cells is a promising field in biomedicine. However, it has been reported that the tissues grown from skin-derived autologous stem cells may still be rejected by the immune system (24). Consequently, the application of autologous MSC transplantation in clinical treatment requires further studies, and there is a great need to investigate transplant-associated rejection reactions, tumorigenicity and the long-term efficacy of autologous MSC transplantation. The methodology of autologous MSC transplantation in the treatment of skin defects induced by various traumas should be improved, and high-quality, multicenter, randomized, double-blind and placebo-controlled trials are required to demonstrate the clinical efficacy of this novel therapy. In addition, certain aspects in particular should be noted. Firstly, the dose of MSCs, observation duration and data units should be standardized and unified, and a widely recognized criteria for assessment of therapeutic efficacy should be employed as far as possible. Additionally, besides the observation of the size of the wound, it is also important that the expanded MSCs be labeled with bromodeoxyuridine (BrdU) prior to transplantation. Full-thickness skin from the wound and the healed skin should be incised between two and 12 weeks after surgery for H\&E staining and BrdU immunohistochemistry to pathologically compare the two. Furthermore, observation reports of adverse reactions and tumorigenesis should be normalized and standardized, and the follow-up period should be extended so that the long-term efficacy may be assessed. In addition, the negative results of the clinical trials should be emphasized and more attention to the ethical issues concerning stem cell therapy should be paid. Finally, the differentiation mechanism and induction conditions of MSCs, and the mechanism underlying their efficacy in the treatment of skin defects, remain unclear (13). It is speculated that MSCs can differentiate into vascular endothelial cells in a wound micro-environment and be further involved in wound repair and promote angiogenesis (25). Additional animal experiments and basic studies are required to observe the transition of MSCs to endothelial cells in local transplantation regions, the release of multiple cytokines in the local region and signal transduction (26).

The novel therapy presented in the current study may solve the current problems of severe wound infection and poor local blood supply in DM, without transplantationrelated rejection reactions and tumor formation, thereby achieving the goals of treatment.

\section{References}

1. Gu YQ: Determination of amputation level in ischaemic lower limbs. ANZ J Surg 74: 31-33, 2004.

2. Yamamoto K, Kondo T, Suzuki S, et al: Molecular evaluation of endothelial progenitor cells in patients with ischemic limbs: therapeutic effect by stem cell transplantation. Arterioscler Thromb Vasc Biol 24: e192-e196, 2004.

3. Inaba S, Egashira K and Komori K: Peripheral-blood or bone marrow mononuclear cells for therapeutic angiogenesis? Lancet 360: 2083; author reply 2084, 2002.

4. Tateishi-Yuyama E, Matsubara H, Murohara $\mathrm{T}$, et al: Therapeutic angiogenesis for patients with limb ischaemia by autologous transplantation of bone marrow cells: a pilot study and a randomised controlled trial. Lancet 360: 427-435, 2002.

5. Hershey JC, Baskin EP, Glass JD, Hartman HA, Gilberto DB Rogers IT and Cook JJ: Revascularization in the rabbit hindlimb: dissociation between capillary sprouting and arteriogenesis. Cardiovasc Res 49:618-625, 2001.

6. Heil M, Ziegelhoeffer T, Mees B and Schaper W: A different outlook on the role of bone marrow stem cells in vascular growth: bone marrow delivers software not hardware. Circ Res 94: 573-574, 2004.

7. Chappell DC, Varner SE, Nerem RM, Medford RM and Alexander RW: Oscillatory shear stress stimulates adhesion molecule expression in cultured human endothelium. Circ Res 82: 532-539, 1998.

8. Coruh A and Yontar Y: Application of split-thickness dermal grafts in deep partial- and full-thickness burns: a new source of auto-skin grafting. J Burn Care Res 33: e94-e100, 2012.

9. Wlaschek M and Scharffetter-Kochanek K: Oxidative stress in chronic venous leg ulcers. Wound Repair Regen 13: 452-461, 2005.

10. Nishida S, Segawa T, Murai I and Nakagawa S: Long-term melatonin administration reduces hyperinsulinemia and improves the altered fatty-acid compositions in type 2 diabetic rats via the restoration of Delta-5 desaturase activity. J Pineal Res 32: 26-33, 2002.

11. Bickenbach JR and Chism E: Selection and extended growth of murine epidermal stem cells in culture. Exp Cell Res 244: 184-195, 1998

12. Oshima H, Rochat A, Kedzia C, Kobayashi K and Barrandon Y: Morphogenesis and renewal of hair follicles from adult multipotent stem cells. Cell 104: 233-245, 2001.

13. Taylor G, Lehrer MS, Jensen PJ, Sun TT and Lavker RM: Involvement of follicular stem cells in forming not only the follicle but also the epidermis. Cell 102: 451-461, 2000.

14. Fang LJ, Fu XB, Sun TZ, et al: An experimental study on the differentiation of bone marrow mesenchymal stem cells into vascular endothelial cells. Zhonghua Shao Shang Za Zhi 19: 22-24, 2003 (In Chinese).

15. Bjornson CR, Rietze RL, Reynolds BA, Magli MC and Vescovi AL: Turning brain into blood: a hematopoietic fate adopted by adult neural stem cells in vivo. Science 283: 534-537, 1999.

16. Mezey E, Chandross KJ, Harta G, Maki RA and McKercher SR: Turning blood into brain: cells bearing neuronal antigens generated in vivo from bone marrow. Science 290: 1779-1782, 2000. 
17. Asahara T, Murohara T, Sullivan A, Silver M, van der Zee R, Li T, Witzenbichler B, Schatteman G and Isner JM: Isolation of putative progenitor endothelial cells for angiogenesis. Science 275: 964-967, 1997.

18. Isner JM and Asahara T: Angiogenesis and vasculogenesis as therapeutic strategies for postnatal neovascularization. J Clin Invest 103: 1231-1236, 1999.

19. Subrammaniyan R, Amalorpavanathan J, Shankar R, et al: Application of autologous bone marrow mononuclear cells in six patients with advanced chronic critical limb ischemia as a result of diabetes: our experience. Cytotherapy 13: 993-999.

20. Yamanaka S: Strategies and new developments in the generation of patient-specific pluripotent stem cells. Cell Stem Cell 1: 39-49, 2007.

21. Wang Y, Huso DL, Harrington J, Kellner J, Jeong DK, Turney J and McNiece IK: Outgrowth of a transformed cell population derived from normal human BM mesenchymal stem cell culture. Cytotherapy 7: 509-519, 2005.
22. Chen Y, Shi L, Zhang L, Li R, Liang J, Yu W, Sun L, Yang X, Wang Y, Zhang Y and Shang Y: The molecular mechanism governing the oncogenic potential of SOX2 in breast cancer. J Biol Chem 283: 17969-17978, 2008.

23. Knoepfler PS: Deconstructing stem cell tumorigenicity: a roadmap to safe regenerative medicine. Stem Cells 27: 1050-1056, 2009.

24. Hayden EC: Stem cells: The growing pains of pluripotency. Nature 473: 272-274, 2011.

25. Yan J,Tie G, Xu TY, Cecchini K and Messina LM: Mesenchymal stem cells as a treatment for peripheral arterialdisease: current status and potential impact of type IIdiabetes on their therapeuticefficacy. Stem Cell Rev 9: 360-372, 2013.

26. Williams AR and Hare JM: Mesenchymal stem cells: biology, pathophysiology, translational findings, and therapeutic implications for cardiac disease. Circ Res 109: 923-940, 2011. 